\title{
No differences in brain microstructure between young Research Paper carriers and non-carriers
}

\author{
Li Hu${ }^{1, *}$, Qunxing $X u^{2, *}$, Jizhen $\mathrm{Li}^{3}$, Feifei $\mathrm{Wang}^{1}$, Xinghua $\mathrm{X} \mathbf{u}^{1}$, Zhiyuan Sun ${ }^{1}$, \\ Xiangxing $\mathrm{Ma}^{1}$, Yong Liu ${ }^{4}$, Qing Wang ${ }^{1}$ and Dawei Wang ${ }^{1}$ \\ ${ }^{1}$ Department of Radiology, Qilu Hospital of Shandong University, Jinan 250012, China \\ ${ }^{2}$ Medical Examination Center, Qilu Hospital of Shandong University, Jinan 250012, China \\ ${ }^{3}$ Mental Health Center of Shandong Province, Jinan 250012, China \\ ${ }^{4}$ Brainnetome Center, National Laboratory of Pattern Recognition, Institute of Automation, Chinese Academy of Sciences, \\ Beijing 100190, China \\ *These authors contributed equally to this work \\ Correspondence to: Dawei Wang, email: daweiwangtj@126.com \\ Qing Wang, email: wangqing663@163.com
}

Keywords: DKl; KIBRA; brain microstructure; young

Received: October 27, $2017 \quad$ Accepted: December 04, $2017 \quad$ Published: December 16, 2017

Copyright: Hu et al. This is an open-access article distributed under the terms of the Creative Commons Attribution License 3.0 (CC BY 3.0), which permits unrestricted use, distribution, and reproduction in any medium, provided the original author and source are credited.

\section{ABSTRACT}

KIBRA rs17070145 polymorphism is associated with variations in memory function and the microstructure of related brain areas. Diffusion kurtosis imaging (DKI) as an extension of diffusion tensor imaging that can provide more information about changes in microstructure, based on the idea that water diffusion in biological tissues is heterogeneous due to structural hindrance and restriction. We used DKI to explore the relationship between KIBRA gene polymorphism and brain microstructure in young adults. We recruited 100 healthy young volunteers, including 53 TT carriers and $47 \mathrm{C}$ allele carriers. No differences were detected between the TT homozygotes and $\mathrm{C}$-allele carriers for any diffusion and kurtosis parameter. These results indicate KIBRA rs17070145 polymorphism likely has little or no effect on brain microstructure in young adults.

\section{INTRODUCTION}

KIBRA gene, also known as WWC1 gene located on chromosome 5q35.1, was first described in 2003 [1]. Gene expression and immunohistological studies showed that KIBRA is expressed in memory-related regions of the brain, such as the hippocampus and cortex, as well as in the cerebellum and the hypothalamus $[2,3]$. At those locations, KIBRA is involved in cellular functions such as synaptogenesis, vesicle transport, transcriptional regulation, cell polarity and migration, and it plays an important role in synaptic plasticity and human memory performance and cognition [1-5].

Genome-wide analyses have shown that KIBRA rs17070145 single nucleotide polymorphism (T-C substitution) is significantly associated with memory performance [6]. Follow-up studies have reported the
KIBRA rs17070145 is associated with episodic memory function and cognitive flexibility [7-10]. Overall, KIBRA $\mathrm{CC}$ homozygotes showed poorer episodic memory performance than T-carriers among healthy subjects. However, two studies failed to confirm an association between the KIBRA polymorphism and episodic memory $[11,12]$. Genetic variation in KIBRA has also been linked to the risk for late-onset Alzheimer's disease (AD), which is associated with severe episodic memory impairment [13-16]. Notably, KIBRA T allele carriers were reportedly at significantly less risk of developing $\mathrm{AD}$ [15]. On the other hand, the $\mathrm{T}$ allele increased the risk of very-lateonset (after the age of 86 years) AD [13]. A recent metaanalysis indicated that the KIBRA T allele had a protective effect, though its impact on AD risk is modest [14].

The effects of KIBRA polymorphism on brain function have been investigated in several neuroimaging 
studies. In a task-based fMRI study, KIBRA CC carriers presented higher brain activation than $\mathrm{T}$ allele carriers in memory-related brain regions, especially the hippocampus and parahippocampal gyrus [6]. Another fMRI study in healthy older subjects showed that in KIBRA CC homozygotes, activation in the hippocampal region was lower than in $\mathrm{T}$ carriers [17]. In a positron emission tomography (PET) study of cognitively normal latemiddle-aged persons, KIBRA rs17070145 CC carriers showed lower glucose metabolism than T-carriers in AD-related brain regions [15]. Through region of interest (ROI)-based analyses, Witte et al. found that KIBRA T-allele carriers had significantly higher hippocampal volume but lower functional connectivity of the left hippocampus [18]. We recently observed in a healthy young cohort that KIBRA $\mathrm{C}$-allele carriers show higher synchronization in the regions of the default mode network $(\mathrm{DMN})$ and executive control network (ECN) than TT carriers [19]. To our knowledge, there has been no study to determine how the KIBRA rs17070145 polymorphism affects the brain microstructure using diffusion kurtosis imaging (DKI) in healthy young adults.

DKI is an extension of diffusion tensor imaging (DTI) that is based on the theory that water diffusion in biological tissues is distribution in non-Gaussian fashion due to structural hindrance and restriction. It is sensitive to tissue microstructure and provides more information about the changes of microstructure. Based on DKI data, both diffusion and kurtosis parameters, including mean kurtosis (MK), axial kurtosis (AK) and radial kurtosis (RK), can be obtained [20-22]. The kurtosis parameters are especially suitable for evaluating microstructural integrity in regions with complex fiber arrangement and isotropic tissues, such as gray matter [23-25]. DKI exhibits improved sensitivity and specificity for detecting developmental and pathological changes in neural tissues and is widely used to assess demyelinating diseases, epilepsy, AD, Parkinson's disease and Huntington's chorea, among others [26, 27].

In the present study, we compared all the diffusion and kurtosis parameters between KIBRA C and TT allele carriers in an effort to explore the relationship between KIBRA gene polymorphism and brain microstructure among healthy young adults.

\section{RESULTS}

\section{Subjects}

100 healthy young Chinese Han subjects with highquality imaging data and KIBRA genotypic information were finally included in this study. These subjects were divided into two groups including 53 TT homozygotes and $47 \mathrm{C}$-allele carriers (37 CT and $10 \mathrm{CC}$ carriers) according to the KIBRA genotypes which was consistent with the previous studies $[19,28]$. There were no significant differences $(p>0.05)$ in age, gender, years of education, between the two groups (Table 1).

\section{Group analysis of DKI parameters}

No significant differences was found between KIBRA TT homozygotes and C-allele carriers in all diffusion and kurtosis parameters with $p$ value $<0.05$ (FDR cor). However, we investigated several differences between the two groups using a relatively loose threshold $(p<0.001$ uncorrected with a minimum cluster size 10).

\section{Group differences in whiter matter (WM)}

Compared with TT homozygotes, KIBRA C-allele carriers showed increased $\mathrm{AxD}$ (axial diffusivity), MD (mean diffusivity), RD (radial diffusivity), decreased AK and $\mathrm{MK}$ in right postcentral gyrus WM. And we found increased $\mathrm{AD}, \mathrm{MD}, \mathrm{RD}$ and decreased KFA (kurtosis fractional anisotropy) in right periventricular WM in KIBRA C-allele carriers. (Figure 1). The results are listed in Table 2.

\section{Group differences in gray matter (GM)}

Relative to TT homozygotes, KIBRA C-allele carriers showed increased $\mathrm{AxD}, \mathrm{MD}, \mathrm{RD}$ in right postcentral gyrus and right insula, decreased $\mathrm{AK}$, MK in right postcentral gyrus, as well as decreased FA (fractional anisotropy), KFA in right caudate head (Figure 2). The results are listed in Table 3. Moreover, KIBRA C-allele carriers showed increased MK and RK in the left parahippocampus, compared to TT homozygotes (Figure 3). The results are listed in Table 4.

\section{DISCUSSION}

To our knowledge, this is the first research using DKI to investigate the effect of KIBRA polymorphism on brain microstructure in healthy young subjects. The study showed no significant difference between KIBRA TT homozygotes and C-allele carriers for any diffusion and kurtosis parameter. However, we investigated several differences between the two groups using a relatively loose threshold. These findings suggest that KIBRA polymorphism likely has little or no influence on brain microstructure in healthy young adults.

Gene expression studies demonstrated that KIBRA is highly expressed in the frontal, parietal and temporal lobes, which are thought to be memory-related brain regions and are more easily impaired than other brain parts [6, 29]. Therefore, the effects of the KIBRA polymorphism on brain functions have been investigated in several neuroimaging studies. A task-based fMRI study recruiting $15 \mathrm{~T}$ carriers and $15 \mathrm{CC}$ carriers demonstrated that KIBRA CC carriers show higher brain activation 
Table 1: Demographic data of subjects

\begin{tabular}{lccc}
\hline & CC+CT & TT & P value \\
\hline Number of subjects & 47 & 53 & \\
age (years) & $25.34(1.54)$ & $25.95(1.75)$ & 0.089 \\
Gender (M/F) & $17 / 30$ & $23 / 30$ & 0.462 \\
Years of education & $17.95(0.27)$ & $18.08(0.23)$ & 0.644 \\
\hline
\end{tabular}

Data are presented as the mean \pm standard deviation (SD). Abbreviation: M, male; F, female.

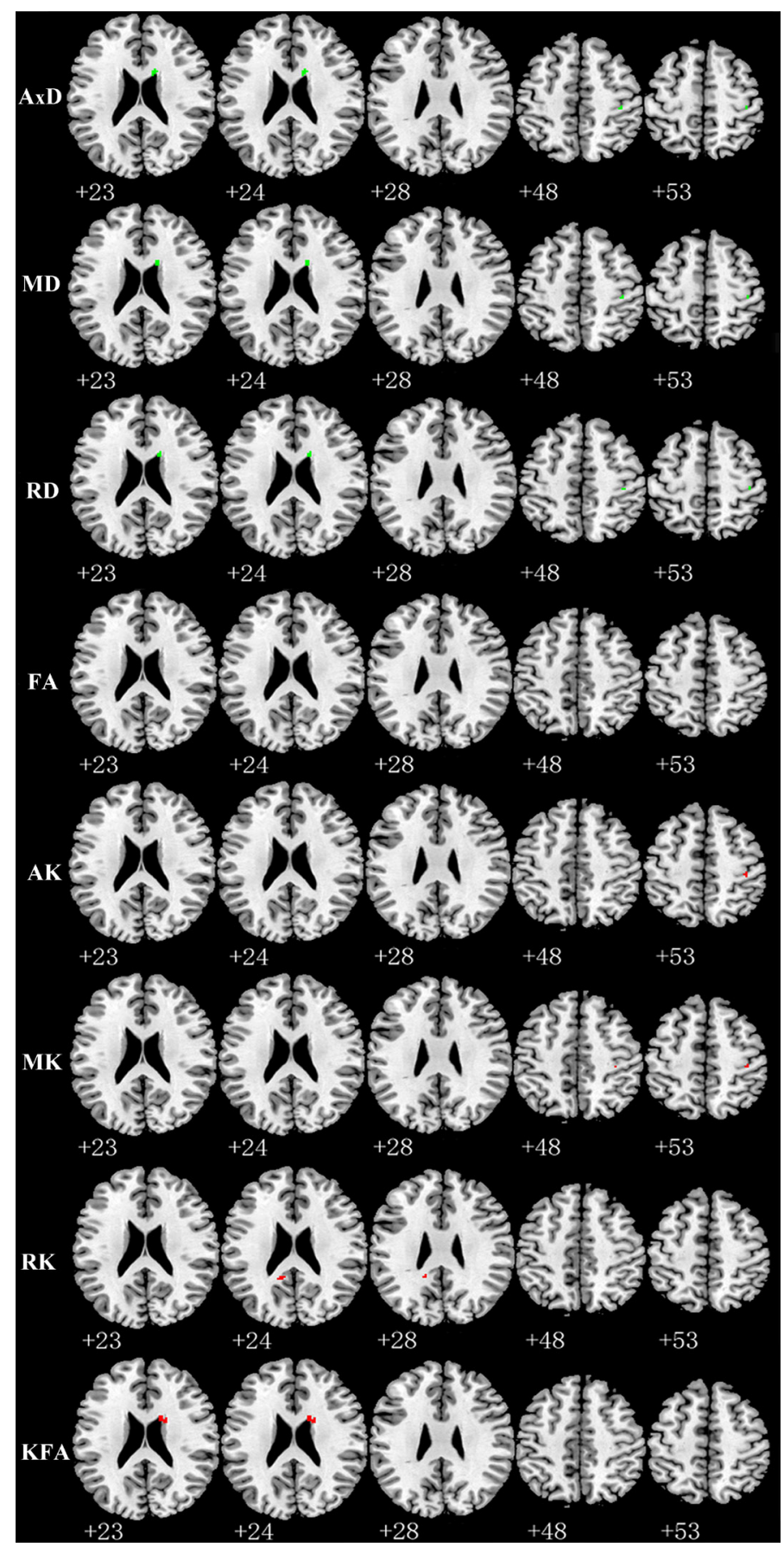

Figure 1: Representative axial images show differences in WM $(p<0.001$, with a minimum cluster size 10) between TT carriers and C carriers for all indices: AxD, MD, RD, FA, AK, MK, RK and KFA. Green and red represents the clusters with increased and decreased indices in KIBRA C-allele carriers compared with TT carriers, respectively. FA showed no difference between the two groups. Abbreviation: AxD: axial diffusivity; MD: mean diffusivity; RD: radial diffusivity; FA: fractional anisotropy; AK: axial kurtosis; MK: mean kurtosis; RK: radial kurtosis; KFA: kurtosis fractional anisotropy. 
Table 2: WM regions showed differences in indices: AxD, MD, RD, AK, KFA, MK and RK between KIBRA TT carriers and $\mathrm{C}$ carriers

\begin{tabular}{|c|c|c|c|c|c|c|c|}
\hline \multirow[t]{2}{*}{ Index } & & \multirow[t]{2}{*}{ Peak MNI Coordinate region } & \multicolumn{3}{|c|}{ Peak MNI coordinates } & \multirow{2}{*}{$\begin{array}{c}\text { Number of cluster } \\
\text { voxels }\end{array}$} & \multirow{2}{*}{$\begin{array}{l}\text { Peak } t \\
\text { value }\end{array}$} \\
\hline & & & $\mathbf{x}$ & $\mathbf{y}$ & $\mathbf{z}$ & & \\
\hline $\mathrm{AxD}$ & 1 & Right Postcentral Gyrus wm & 38 & -27 & 50 & 11 & 3.95 \\
\hline \multirow{3}{*}{ MD } & 2 & Right Lateral Ventricle wm & 12 & 12 & 20 & 27 & 4.05 \\
\hline & 1 & Right Postcentral Gyrus wm & 38 & -27 & 50 & 14 & 3.97 \\
\hline & 2 & Right Lateral Ventricle wm & 16 & 12 & 20 & 22 & 3.91 \\
\hline \multirow[t]{2}{*}{$\mathrm{RD}$} & 1 & Right Postcentral Gyrus wm & 38 & -27 & 52 & 12 & 3.88 \\
\hline & 2 & Right Lateral Ventricle wm & 16 & 12 & 20 & 18 & 3.98 \\
\hline \multirow[t]{2}{*}{ AK } & 1 & Right Postcentral Gyrus wm & 40 & -27 & 56 & 11 & 3.90 \\
\hline & 2 & Left Precentral Gyrus wm & -40 & -11 & 34 & 12 & 5.21 \\
\hline \multirow{3}{*}{$\begin{array}{l}\text { KFA } \\
\mathrm{MK}\end{array}$} & 1 & Right Lateral Ventricle wm & 20 & 4 & 22 & 28 & 4.02 \\
\hline & 1 & Right Postcentral Gyrus wm & 40 & -25 & 56 & 19 & 3.96 \\
\hline & 2 & Right Medial Frontal Gyrus wm & 14 & 40 & 32 & 11 & 3.91 \\
\hline RK & 1 & Left Cingulate Gyrus wm & -14 & -45 & 26 & 16 & 3.75 \\
\hline
\end{tabular}

Abbreviation: AxD: axial diffusivity; MD: mean diffusivity; RD: radial diffusivity; FA: fractional anisotropy; AK: axial kurtosis; MK: mean kurtosis; RK: radial kurtosis; KFA: kurtosis fractional anisotropy.

than $\mathrm{T}$ allele carriers in memory-related brain regions (especially the hippocampus and parahippocampal gyrus) [6]. The CC carriers needed more brain activation to perform as well as the T carriers. Another fMRI study including 83 samples from 55- to 60-year-old individuals without dementia showed that KIBRA CC homozygotes had lower hippocampal activation than T carriers [17]. In a PET-CT study of cognitively normal late-middleaged persons incorporating $67 \mathrm{CC}$ carriers and $69 \mathrm{~T}$ carriers, KIBRA rs 17070145 CC carriers showed lower glucose metabolism than T-carriers in AD-related brain regions (posterior cingulate and precuneus regions) [15]. The findings in the healthy old were opposite to those in the young. One possible explanation for this is that KIBRA-C carriers require more brain activity in memoryrelated brain regions to maintain normal cognition in the young, but this compensatory response is lost by the time individuals reach later stages of life. As a result, KIBRA-C carriers show poorer cognitive performance.

In our study, there was no significant difference between KIBRA TT homozygotes and C-allele carriers in any diffusion or kurtosis parameter. Histologic examinations in brains from AD model mice and human studies suggest increased diffusion parameters with decreased FA reflect demyelination and loss of axons in whiter matter. The decreased kurtosis parameters reflected the loss of neuron cell bodies, synapses and dendrites in gray matter [30-32]. In the young, the KIBRA polymorphism has no or little effect on brain microstructure. DKI parameters may not be sensitive enough to detect the brain microstructural differences between KIBRA TT homozygotes and C-allele carriers, although brain function has changed. The APOE 4 allele is associated with a high risk for $\mathrm{AD}$ [33], and several studies have investigated the effects of APOE polymorphism on brain microstructure. One study including 575 healthy adolescents found no difference in white matter microstructural organization between carriers and noncarriers of the APOE 4 allele, based on diffusion tensor imaging parameters [34]. Another study incorporating 1412 healthy adolescents reported no differences in hippocampal volume between APOE 4 carriers and non-carriers were found [35]. However, a study including 44 healthy subjects between 20 and 38 years of age found that hippocampal volume was reduced in healthy young APOE 4 carriers relative to non-carriers [36]. Moreover, a majority of studies in older individuals and AD patients demonstrated that APOE 4 carriers show greater rates of temporal lobe atrophy [37, 38]. Lindenberger and colleagues hypothesized that genetic effects in younger adults may be small or undetectable, but these effects become more pronounced as people age [39]. Similarly, the effects of KIBRA rs17070145 polymorphism may not be apparent until later adulthood.

Using a relatively loose threshold, we found increased $\mathrm{AxD}, \mathrm{MD}, \mathrm{RD}$, decreased $\mathrm{AK}$ and $\mathrm{MK}$ in right postcentral gyrus, which is a key region of the sensorimotor network. In addition, there is increasing evidence for sensorimotor dysfunction early in the disease [40]. For example, in healthy young subjects, APOE $\varepsilon 4$ carriers exhibited increased functional connectivity in the sensorimotor network [41]. Evidence from behavioral studies in elderly individuals indicates that APOE $\varepsilon 4$ carriers have greater vulnerability for impaired motor function [42]. fMRI studies have revealed that sensorimotor network connectivity is decreased or rewired in $\mathrm{AD}$ [43]. A resting-state network study revealed that the sensorimotor network exhibits decreased connectivity in healthy elders with APOE $\varepsilon 4$ [44]. The increased AxD, MD, RD, decreased AK and MK in the right postcentral gyrus might be an indicator for the impairment of the regional microstructure.

Another interesting finding was that KIBRA C allele carriers showed greater $\mathrm{MK}$ and $\mathrm{RK}$ in the left parahippocampus than TT homozygotes. In contrast to 


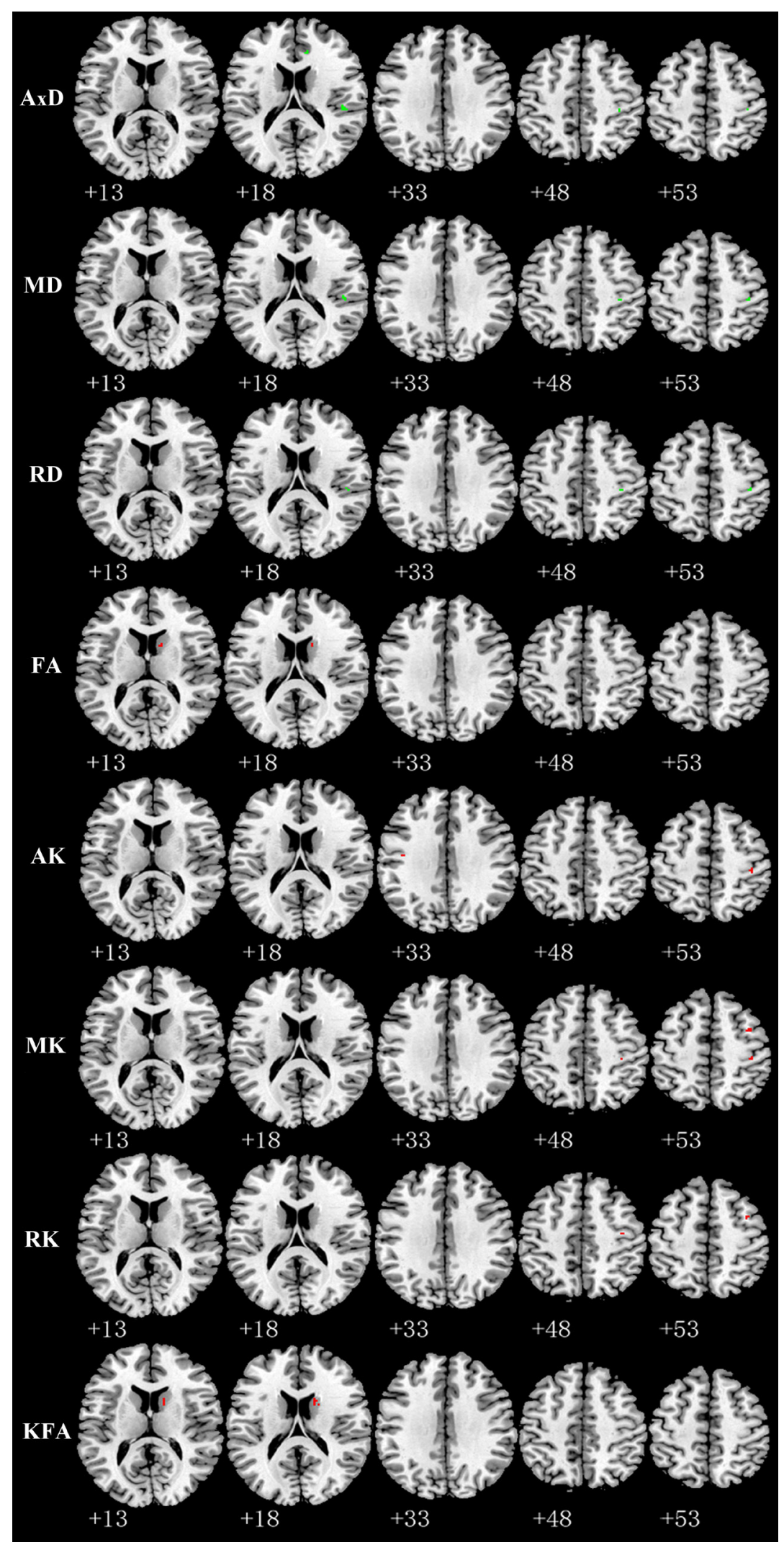

Figure 2: Representative axial images show GM regions differences $(p<0.001$, with a minimum cluster size 10) between TT carriers and $\mathrm{C}$ carriers for all indices: AxD, MD, RD, FA, AK, MK, RK, and KFA. Green and red represents the clusters with increased and decreased indices in KIBRA C-allele carriers compared with TT carriers, respectively. Abbreviation: AxD: axial diffusivity; MD: mean diffusivity; RD: radial diffusivity; FA: fractional anisotropy; AK: axial kurtosis; MK: mean kurtosis; RK: radial kurtosis; KFA: kurtosis fractional anisotropy. 
Table 3: GM regions showed differences in indices: AxD, MD, RD, FA, AK, KFA, MK and RK between KIBRA TT carriers and $\mathrm{C}$ carriers

\begin{tabular}{|c|c|c|c|c|c|c|c|}
\hline \multirow[t]{2}{*}{ Index } & & \multirow[t]{2}{*}{ Peak MNI coordinate region } & \multicolumn{3}{|c|}{ Peak MNI coordinates } & \multirow[t]{2}{*}{ Number of cluster voxels } & \multirow[t]{2}{*}{ Peak $t$ value } \\
\hline & & & $\mathbf{x}$ & $\mathbf{y}$ & $\mathbf{z}$ & & \\
\hline \multirow[t]{3}{*}{$\mathrm{AxD}$} & 1 & Right Postcentral Gyrus & 38 & -27 & 50 & 12 & 3.94 \\
\hline & 2 & Right Insula & 48 & -28 & 20 & 17 & 4.18 \\
\hline & 3 & Right Anterior Cingulate & 10 & 34 & 20 & 16 & 4.20 \\
\hline \multirow{2}{*}{ MD } & 1 & Right Postcentral Gyrus & 38 & -27 & 50 & 14 & 3.94 \\
\hline & 2 & Right Insula & 48 & -30 & 20 & 16 & 4.11 \\
\hline \multirow{3}{*}{$\mathrm{RD}$} & 1 & Right Postcentral Gyrus & 38 & -27 & 52 & 12 & 3.88 \\
\hline & 2 & Right Insula & 48 & -28 & 20 & 14 & 4.04 \\
\hline & 3 & Lingual Gyrus & 6 & -82 & -10 & 10 & 3.91 \\
\hline FA & 1 & Right Caudate Head & 14 & 10 & 16 & 12 & 4.49 \\
\hline \multirow[t]{2}{*}{$\mathrm{AK}$} & 1 & Right Postcentral Gyrus & 40 & -27 & 56 & 11 & 3.90 \\
\hline & 2 & Left Precentral Gyrus & -40 & -11 & 34 & 10 & 5.21 \\
\hline KFA & 1 & Right Caudate Head & 20 & 6 & 20 & 39 & 4.02 \\
\hline $\mathrm{MK}$ & 1 & Right Postcentral Gyrus & 40 & -25 & 56 & 19 & 3.96 \\
\hline \multirow[t]{4}{*}{ RK } & 2 & Right Middle Frontal Gyrus & 36 & 2 & 54 & 13 & 3.80 \\
\hline & 1 & Right Precentral Gyrus & 38 & -13 & 48 & 10 & 3.48 \\
\hline & 2 & Right Middle Frontal Gyrus & 36 & 4 & 54 & 12 & 3.87 \\
\hline & 3 & Left Precuneus & -20 & -65 & 42 & 10 & 3.77 \\
\hline
\end{tabular}

Abbreviation: AxD: axial diffusivity; MD: mean diffusivity; RD: radial diffusivity; FA: fractional anisotropy; AK: axial kurtosis; MK: mean kurtosis; RK: radial kurtosis; KFA: kurtosis fractional anisotropy.

conventional DTI parameters, MK and RK are regarded as indices of the complexity of tissue microstructure, reflecting the density, orientation, and degree of organization of cell membranes, axon sheaths, and myelin layers [20, 4547]. Using diffusion kurtosis imaging with a cohort the included individuals with AD or mild cognitive impairment (MCI) and normal controls, Gong et al. recently reported significantly decreased hippocampal MK in MCI and AD, which reflects the loss of microstructural compartments such as neuronal cell bodies, axons, synapses, and dendrites. In addition, using resting fMRI, Filippini et al. [48] detected greater default mode network synchronization involving medial temporal and medial-prefrontal cortical areas in APOE $\varepsilon 4$-carriers than noncarriers. Our results are, to some extent, consistent with these studies. Increased MK and RK in the left parahippocampus in healthy young KIBRA C allele carriers likely reflects a compensatory mechanism to maintain relatively normal memory function.

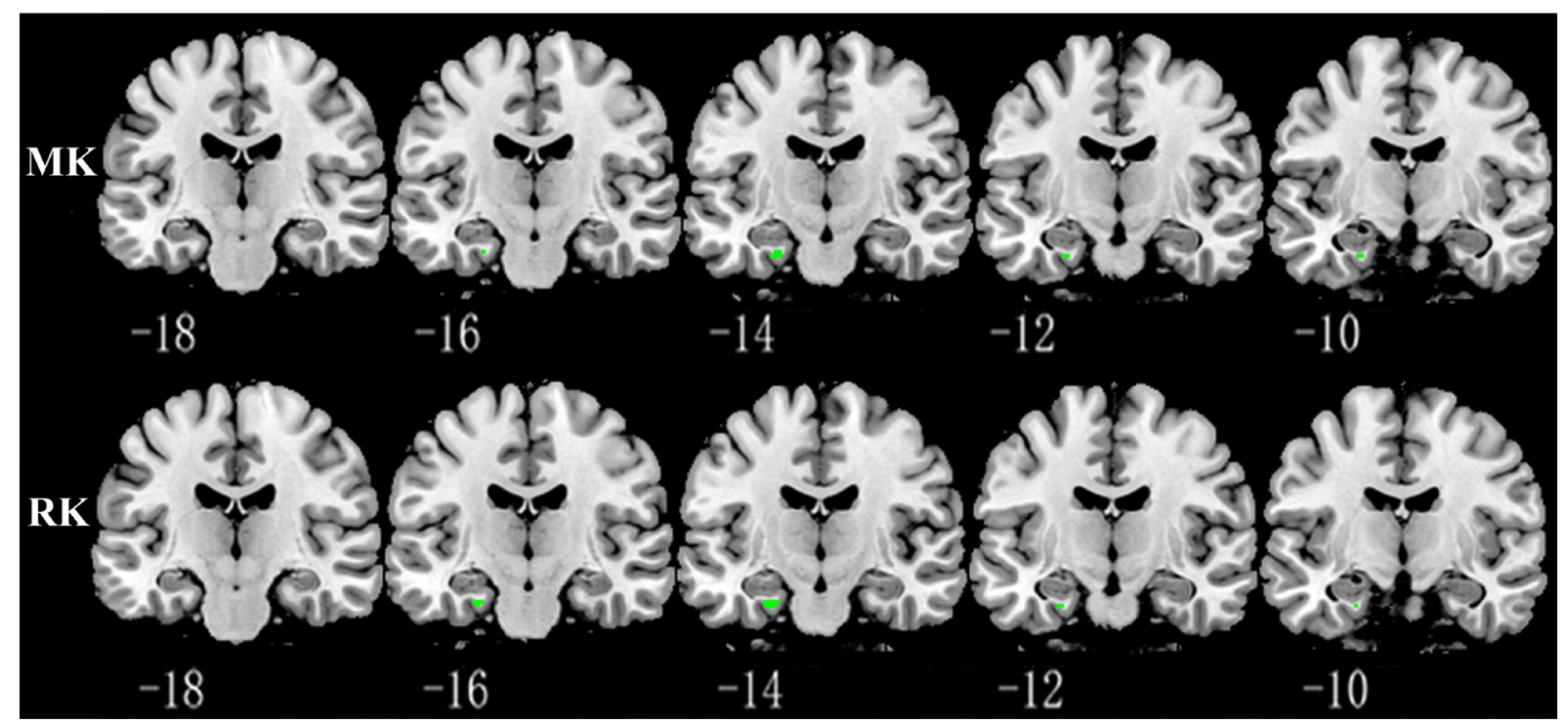

Figure 3: Representative coronal images show increased MK and RK in parahippocampus $(p<0.001$, with a minimum cluster size 10) in KIBRA C-allele carriers compared with TT carriers. Abbreviation: MK: mean kurtosis; RK: radial kurtosis. 
Table 4: GM regions showed increased MK and RK in parahippocampus in KIBRA C-allele carriers compared with TT carriers

\begin{tabular}{|c|c|c|c|c|c|c|c|}
\hline \multirow[t]{2}{*}{ Index } & & \multirow[t]{2}{*}{ Peak MNI coordinate region } & \multicolumn{3}{|c|}{ Peak MNI coordinates } & \multirow[t]{2}{*}{ Number of cluster voxels } & \multirow[t]{2}{*}{ Peak t value } \\
\hline & & & $\mathbf{x}$ & $\mathbf{y}$ & $\mathbf{z}$ & & \\
\hline MK & 1 & Left Parahippocampa Gyrus & -24 & -14 & -28 & 10 & -3.83 \\
\hline RK & 2 & Left Parahippocampa Gyrus & -24 & -14 & -28 & 14 & -4.00 \\
\hline
\end{tabular}

Abbreviation: MK: mean kurtosis; RK: radial kurtosis.

There are several limitations to the present study. First, the small number of CC-individuals (10/100) made our grouping method different from most studies, though our previous studies suggest combining the $\mathrm{CC}$ and CT individuals is reasonable, at least in the Chinese population. A much larger sample should be collected in the future, especially KIBRA CC homozygotes. Second, other gene polymorphisms associated with memory or cognitive function (e.g. BDNF and CLSTN2) were not controlled in this study, which may bias our results. Finally, we mainly focused on microstructural changes in healthy young adults. This same approach could be used to determine whether an effect of KIBRA polymorphism on brain microstructure is more apparent in cognitively intact older adults and in $\mathrm{AD}$ patients.

In summary, no significant differences were investigated between KIBRA rs17070145 TT homozygotes and $\mathrm{C}$-allele carriers in all diffusion and kurtosis parameters in healthy young adults. And these results suggest that KIBRA rs17070145 polymorphism might have no or slight effect on brain microstructure of young. However, the effect of KIBRA rs17070145 polymorphism on brain microstructure may occur or become more obvious later in life.

\section{MATERIALS AND METHODS}

\section{Subjects}

A total of 125 healthy young Chinese subjects (mean age: $25 \pm 1.54$ years; ranging 23-28 years; 68 females, 57 males;) were recruited in this study after giving written informed consent, in accordance with Medical Ethics Committee of Qilu Hospital of Shandong University. Careful screening was performed to ensure that all participants were free of any lifetime history of psychiatric or neurological illness, psychiatric treatment, or drug or alcohol abuse, and MR contraindications. To avoid population stratification artifacts, only Chinese Han subjects were included. Finally, we recruited 100 healthy young with right-handed subjects from 125 subjects. Twenty-five subjects were excluded from further study owing to lack of genetic data or poor imaging during the MRI examinations.

\section{Genotyping}

Fasting venous blood was collected from the peripheral vein. DNA was extracted using a Puregene kit
(Gentra Systems, Inc., Minneapolis, MN, USA). Quality control was performed at the DNA-sample level, assay level, and the level of multiplex assay pool. The call rates for the SNPs included in this study were between 99.4 and $99.7 \%$. KIBRA rs17070145 was genotyped using the Sequenom Mass Array system (Sequenom Inc., San Diego, CA, USA) with technical support from CapitalBio Technology (Beijing, China). Mass determination was carried out with the MALDI-TOF mass spectrometer and Mass ARRAY Type 4.0 software was used for data acquisition.

Among individuals included in the study, frequencies of genotypes in the KIBRA rs17070145 polymorphism were $\mathrm{T} / \mathrm{T}$ in 53 subjects $(53 \%), \mathrm{C} / \mathrm{T}$ in 37 subjects (37\%), and $\mathrm{C} / \mathrm{C}$ in 10 subjects (10\%). Allelic frequencies were in line with previous reports and Hardy Weinberg Equilibrium was $p=0.62$ for $\operatorname{rs} 17070145$.

\section{Image acquisition}

Images were acquired in a Siemens verio 3.0 Tesla MR scanner (Erlangen, Germany) with a 8-channel head coil with soft foam padding. DKI images were acquired with $3 b$-values ( $b=0,1000$ and $2000 \mathrm{~s} / \mathrm{mm}^{2}$ ) along 20 diffusion gradient directions using a single-shot, spinecho EPI sequence. Other imaging parameters were: TR $=9600 \mathrm{~ms}, \mathrm{TE}=96 \mathrm{~ms} ; \mathrm{FOV}=256 \times 256 \mathrm{~mm}^{2}$; matrix $=$ $128 \times 128$; voxel $=2 \times 2 \times 3 \mathrm{~mm}^{3} ; 45$ axial slices; slice thickness $3.0 \mathrm{~mm}$. Sagittal 3D T1-weighted images were acquired by magnetization prepared rapid acquisition gradient echo (MPRAGE) sequence $(\mathrm{TR} / \mathrm{TE}=2000 / 2.3$ $\mathrm{ms}$; inversion time $=900 \mathrm{~ms} ; \mathrm{FA}=9^{\circ}$; matrix $=256 \times 256$; slice thickness $=1 \mathrm{~mm}$, no gap; 192 slices).

\section{Data analysis}

Eddy current-induced distortion and motion artifacts in the DKI dataset were corrected using affine alignment of each diffusion weighted image to the $b=0$ image using FMRIB's diffusion toolbox (FSL 4.0, http://www. fmrib.ox.ac.uk/fsl) [49]. After skull-stripping, Diffusional Kurtosis Estimator (http://www.nitrc.org/projects/dke) was implemented to calculate the diffusion and kurtosis tensors including mean kurtosis (MK), axial kurtosis (AK), radial kurtosis (RK), kurtosis fractional anisotropy (KFA) as well as fractional anisotropy (FA), mean diffusivity (MD), axial diffusivity $(\mathrm{AxD})$, and radial diffusivity $(\mathrm{RD})$. Voxel-based 
analysis was as follows: Firstly, all the b0 $(b=0)$ images were normalized to the EPI template using coregistration tool in the SPM8 (http://www.fil.ion.ucl.ac.uk/spm/), with a reslicing resolution of $2 \times 2 \times 2 \mathrm{~mm}^{3}$. Afterwards, these normalized b0 images were averaged and smoothed with a full width at half maximum (FWHM) kernel of $6 \times 6$ $\times 6 \mathrm{~mm}^{3}$ to generate a new subject-specific b0 template. Secondly, all the b0 images were again normalized to the new b0 template to get the transformation information, which was then applied to all of the corresponding parametric maps. Then all the parametric maps were smoothed using a FWHM kernel of $6 \times 6 \times 6 \mathrm{~mm}^{3}$ to reduce possible error in local anatomy. For each subject, the sagittal T1-weighted image was segmented into GM, WM and cerebrospinal fluid in voxel-based morphometry (VBM8, http://dbm.neuro.uni-jena.de/vbm8/), which were then normalized to the standard Montreal Neurological Institute (MNI) space using SPM8 with a reslicing resolution of $2 \times 2 \times 2 \mathrm{~mm}^{3}$. The normalized GM and WM images for each subject were averaged and smoothed with a $6 \mathrm{~mm}$ FWHM Gaussian kernel, the mean of which, including all voxels with a GM probability greater than 0.3 , WM greater than 0.4 were converted into masks.

\section{Statistical analysis}

Group comparisons of these data were performed using a $\chi^{2}$ test for categorical variables and $t$-tests for continuous variables. Significance level was set at $p<0.05$ with two-tailed tests. Two-sample tests were applied to detect WM and GM differences in all diffusion and kurtosis parameters between TT homozygotes and C-allele carriers with $p$ value $<0.05$, False Discovery Rate (FDR) corrected.

\section{Author contribution}

Dawei Wang and Li Hu conducted the experiments and wrote the manuscript. Xinghua $\mathrm{Xu}$, Zhiyuan Sun, Xiangxing Ma, Yong Liu participated in the experiments. Jizhen Li, Feifei Wang and Qunxing Xu collected and analyzed data. Qing Wang contributed to the study design.

\section{ACKNOWLEDGMENTS} families.

We would gratefully thank for the patients and their

\section{CONFLICTS OF INTEREST}

There are no conflicts of interest.

\section{FUNDING}

This study was supported by grants from the National Natural Science Foundation of China (Grant nos: 81400890, 81571062), Shandong Provincial Key Research and Development Program (Grant nos: 2017GSF218093，2017CXGC1502，2017CXGC1504), Shandong Provincial Science and Technology Major Project (Emerging Industry) (Grant no. 2015ZDXX0801A01), the Fundamental Research Funds of Shandong University (Grant no.2017JC013).

\section{REFERENCES}

1. Kremerskothen J, Plaas C, Buther K, Finger I, Veltel S, Matanis T, Liedtke T, Barnekow A. Characterization of KIBRA, a novel WW domain-containing protein. Biochem Biophys Res Commun. 2003; 300:862-7. https://doi. org/10.1016/S0006-291X(02)02945-5.

2. Schneider A, Huentelman MJ, Kremerskothen J, Duning K, Spoelgen R, Nikolich K. KIBRA: A New Gateway to Learning and Memory? Front Aging Neurosci. 2010; 2:4. https://doi.org/10.3389/neuro.24.004.2010.

3. Zhang L, Yang S, Wennmann DO, Chen Y, Kremerskothen J, Dong J. KIBRA: In the brain and beyond. Cell Signal. 2014; 26:1392-9. https://doi.org/10.1016/j.cellsig.2014.02.023.

4. Vogt-Eisele A, Kruger C, Duning K, Weber D, Spoelgen R, Pitzer C, Plaas C, Eisenhardt G, Meyer A, Vogt G, Krieger M, Handwerker E, Wennmann DO, et al. KIBRA (KIdney/BRAin protein) regulates learning and memory and stabilizes Protein kinase Mzeta. J Neurochem. 2014; 128:686-700. https://doi.org/10.1111/jnc.12480.

5. Duning K, Schurek EM, Schluter M, Bayer M, Reinhardt HC, Schwab A, Schaefer L, Benzing T, Schermer B, Saleem MA, Huber TB, Bachmann S, Kremerskothen J, et al. KIBRA modulates directional migration of podocytes. J Am Soc Nephrol. 2008; 19:1891-903. https://doi.org/10.1681/ ASN.2007080916.

6. Papassotiropoulos A, Stephan DA, Huentelman MJ, Hoerndli FJ, Craig DW, Pearson JV, Huynh KD, Brunner F, Corneveaux J, Osborne D, Wollmer MA, Aerni A, Coluccia D, et al. Common Kibra alleles are associated with human memory performance. Science. 2006; 314:475-8. https:// doi.org/10.1126/science.1129837.

7. Bates TC, Price JF, Harris SE, Marioni RE, Fowkes FG, Stewart MC, Murray GD, Whalley LJ, Starr JM, Deary IJ. Association of KIBRA and memory. Neurosci Lett. 2009; 458:140-3. https://doi.org/10.1016/j.neulet.2009.04.050.

8. Yasuda Y, Hashimoto R, Ohi K, Fukumoto M, Takamura H, Iike N, Yoshida T, Hayashi N, Takahashi H, Yamamori H, Morihara T, Tagami S, Okochi M, et al. Association study of KIBRA gene with memory performance in a Japanese population. World J Biol Psychiatry. 2010; 11:852-7. https://doi.org/10.3109/15622971003797258.

9. Vassos E, Bramon E, Picchioni M, Walshe M, Filbey FM, Kravariti E, McDonald C, Murray RM, Collier DA, Toulopoulou T. Evidence of association of KIBRA genotype with episodic memory in families of psychotic patients 
and controls. J Psychiatr Res. 2010; 44:795-8. https://doi. org/10.1016/j.jpsychires.2010.01.012.

10. Schaper K, Kolsch H, Popp J, Wagner M, Jessen F. KIBRA gene variants are associated with episodic memory in healthy elderly. Neurobiology of Aging. 2008; 29:1123-5. https://doi.org/10.1016/j.neurobiolaging.2007.02.001.

11. Need AC, Attix DK, McEvoy JM, Cirulli ET, Linney KN, Wagoner AP, Gumbs CE, Giegling I, Moller HJ, Francks C, Muglia P, Roses A, Gibson G, et al. Failure to replicate effect of Kibra on human memory in two large cohorts of European origin. Am J Med Genet B Neuropsychiatr Genet. 2008; 147B:667-8. https://doi.org/10.1002/ajmg.b.30658.

12. Wersching $H$, Guske $K$, Hasenkamp S, Hagedorn $C$, Schiwek S, Jansen S, Witte V, Wellmann J, Lohmann H, Duning K, Kremerskothen J, Knecht S, Brand E, et al. Impact of common KIBRA allele on human cognitive functions. Neuropsychopharmacology. 2011; 36:1296-304. https://doi.org/10.1038/npp.2011.16.

13. Rodriguez-Rodriguez E, Infante J, Llorca J, Mateo I, Sanchez-Quintana C, Garcia-Gorostiaga I, Sanchez-Juan P, Berciano J, Combarros O. Age-dependent association of KIBRA genetic variation and Alzheimer's disease risk. Neurobiol Aging. 2009; 30:322-4. https://doi.org/10.1016/j. neurobiolaging.2007.07.003.

14. Burgess JD, Pedraza O, Graff-Radford NR, Hirpa M, Zou F, Miles R, Nguyen T, Li M, Lucas JA, Ivnik RJ, Crook J, Pankratz VS, Dickson DW, et al. Association of common KIBRA variants with episodic memory and AD risk. Neurobiol Aging. 2011; 32:557 e1-9. https://doi. org/10.1016/j.neurobiolaging.2010.11.004.

15. Corneveaux JJ, Liang WS, Reiman EM, Webster JA, Myers AJ, Zismann VL, Joshipura KD, Pearson JV, Hu-Lince D, Craig DW, Coon KD, Dunckley T, Bandy D, et al. Evidence for an association between KIBRA and late-onset Alzheimer's disease. Neurobiol Aging. 2010; 31:901-9. https://doi.org/10.1016/j.neurobiolaging.2008.07.014.

16. Almeida OP, Schwab SG, Lautenschlager NT, Morar B, Greenop KR, Flicker L, Wildenauer D. KIBRA genetic polymorphism influences episodic memory in later life, but does not increase the risk of mild cognitive impairment. J Cell Mol Med. 2008; 12:1672-6. https://doi. org/10.1111/j.1582-4934.2008.00229.x.

17. Kauppi K, Nilsson LG, Adolfsson R, Eriksson E, Nyberg L. KIBRA polymorphism is related to enhanced memory and elevated hippocampal processing. J Neurosci. 2011; 31:14218-22. https://doi.org/10.1523/ JNEUROSCI.3292-11.2011.

18. Witte AV, Kobe T, Kerti L, Rujescu D, Floel A. Impact of KIBRA Polymorphism on Memory Function and the Hippocampus in Older Adults. Neuropsychopharmacology. 2016; 41:781-90. https://doi.org/10.1038/npp.2015.203.

19. Wang D, Liu B, Qin W, Wang J, Zhang Y, Jiang T, Yu C. KIBRA gene variants are associated with synchronization within the default-mode and executive control networks.
Neuroimage. 2013; 69:213-22. https://doi.org/10.1016/j. neuroimage.2012.12.022.

20. Jensen JH, Helpern JA, Ramani A, Lu H, Kaczynski K. Diffusional kurtosis imaging: the quantification of nongaussian water diffusion by means of magnetic resonance imaging. Magn Reson Med. 2005; 53:1432-40. https://doi. org/10.1002/mrm.20508.

21. Wu EX, Cheung MM. MR diffusion kurtosis imaging for neural tissue characterization. NMR Biomed. 2010; 23:836-48. https:// doi.org/10.1002/nbm.1506.

22. Jensen JH, Helpern JA. MRI quantification of non-Gaussian water diffusion by kurtosis analysis. NMR Biomed. 2010; 23:698-710. https://doi.org/10.1002/nbm.1518.

23. Gong NJ, Wong CS, Chan CC. Correlations between microstructural alterations and severity of cognitive deficiency in Alzheimer's disease and mild cognitive impairment: a diffusional kurtosis imaging study. Magnetic Resonance Imaging. 2013; 31:688-94. https://doi. org/10.1016/j.mri.2012.10.027.

24. Lazar M, Jensen JH, Xuan L, Helpern JA. Estimation of the orientation distribution function from diffusional kurtosis imaging. Magn Reson Med. 2008; 60:774-81. https://doi. org/10.1002/mrm.21725.

25. Hori M, Fukunaga I, Masutani Y, Taoka T, Kamagata K, Suzuki Y, Aoki S. Visualizing non-Gaussian diffusion: clinical application of q-space imaging and diffusional kurtosis imaging of the brain and spine. Magn Reson Med Sci. 2012; 11:221-33. https://doi.org/10.2463/mrms.11.221.

26. Giannelli M, Toschi N, Passamonti L, Mascalchi M, Diciotti $\mathrm{S}$, Tessa C. Diffusion kurtosis and diffusion-tensor MR imaging in Parkinson disease. Radiology. 2012; 265:645-6; author reply 6-7. https://doi.org/10.1148/radiol.12121036.

27. Hansen B, Shemesh N, Jespersen SN. Fast imaging of mean, axial and radial diffusion kurtosis. Neuroimage. 2016; 142:381-93. https://doi.org/10.1016/j.neuroimage.2016.08.022.

28. Vyas NS, Ahn K, Stahl DR, Caviston P, Simic M, Netherwood S, Puri BK, Lee Y, Aitchison KJ. Association of KIBRA rs17070145 polymorphism with episodic memory in the early stages of a human neurodevelopmental disorder. Psychiatry Res. 2014; 220:37-43. https://doi. org/10.1016/j.psychres.2014.07.024.

29. Johannsen S, Duning K, Pavenstadt H, Kremerskothen J, Boeckers TM. Temporal-spatial expression and novel biochemical properties of the memory-related protein KIBRA. Neuroscience. 2008; 155:1165-73. https://doi. org/10.1016/j.neuroscience.2008.06.054.

30. Sykova E, Vorisek I, Antonova T, Mazel T, MeyerLuehmann M, Jucker M, Hajek M, Ort M, Bures J. Changes in extracellular space size and geometry in APP23 transgenic mice: a model of Alzheimer's disease. Proc Natl Acad Sci U S A. 2005; 102:479-84. https://doi.org/10.1073/ pnas.0408235102.

31. Chen H, Epelbaum S, Delatour B. Fiber Tracts Anomalies in APPxPS1 Transgenic Mice Modeling Alzheimer's 
Disease. J Aging Res. 2011; 2011:281274. https://doi. org/10.4061/2011/281274.

32. Schmierer K, Tozer DJ, Scaravilli F, Altmann DR, Barker GJ, Tofts PS, Miller DH. Quantitative magnetization transfer imaging in postmortem multiple sclerosis brain. J Magn Reson Imaging. 2007; 26:41-51. https://doi. org/10.1002/jmri.20984.

33. Scarmeas N, Stern Y. Imaging studies and APOE genotype in persons at risk for Alzheimer's disease. Current Psychiatry Reports. 2006; 8:11-7. https://doi.org/10.1007/ s11920-996-0057-4.

34. Dell'Acqua F, Khan W, Gottlieb N, Giampietro V, Ginestet C, Bouls D, Newhouse S, Dobson R, Banaschewski T, Barker GJ, Bokde AL, Buchel C, Conrod P, et al. Tract Based Spatial Statistic Reveals No Differences in White Matter Microstructural Organization between Carriers and Non-Carriers of the APOE varepsilon4 and varepsilon2 Alleles in Young Healthy Adolescents. J Alzheimers Dis. 2015; 47:977-84. https://doi.org/10.3233/JAD-140519.

35. Khan W, Giampietro V, Ginestet C, Dell'Acqua F, Bouls D, Newhouse S, Dobson R, Banaschewski T, Barker GJ, Bokde AL, Buchel C, Conrod P, Flor H, et al. No differences in hippocampal volume between carriers and non-carriers of the ApoE epsilon4 and epsilon2 alleles in young healthy adolescents. J Alzheimers Dis. 2014; 40:37-43. https://doi. org/10.3233/JAD-131841.

36. O'Dwyer L, Lamberton F, Matura S, Tanner C, Scheibe M, Miller J, Rujescu D, Prvulovic D, Hampel H. Reduced hippocampal volume in healthy young ApoE4 carriers: an MRI study. PLoS One. 2012; 7:e48895. https://doi. org/10.1371/journal.pone.0048895.

37. Du AT, Schuff N, Chao LL, Kornak J, Jagust WJ, Kramer JH, Reed BR, Miller BL, Norman D, Chui HC, Weiner MW. Age effects on atrophy rates of entorhinal cortex and hippocampus. Neurobiol Aging. 2006; 27:733-40. https:// doi.org/10.1016/j.neurobiolaging.2005.03.021.

38. Filippini N, Rao A, Wetten S, Gibson RA, Borrie M, Guzman D, Kertesz A, Loy-English I, Williams J, Nichols T, Whitcher B, Matthews PM. Anatomicallydistinct genetic associations of APOE epsilon4 allele load with regional cortical atrophy in Alzheimer's disease. Neuroimage. 2009; 44:724-8. https://doi.org/10.1016/j. neuroimage.2008.10.003.

39. Lindenberger U, Nagel IE, Chicherio C, Li SC, Heekeren HR, Backman L. Age-related decline in brain resources modulates genetic effects on cognitive functioning. Front Neurosci. 2008; 2:234-44. https://doi.org/10.3389/ neuro.01.039.2008.

40. Albers MW, Gilmore GC, Kaye J, Murphy C, Wingfield A, Bennett DA, Boxer AL, Buchman AS, Cruickshanks KJ, Devanand DP. At the interface of sensory and motor dysfunctions and Alzheimer's disease. Alzheimers \& Dementia. 2015; 11:70-98. https://doi.org/10.1016/j. jalz.2014.04.514.
41. Filippini N, Macintosh BJ, Hough MG, Goodwin GM, Frisoni GB, Smith SM, Matthews PM, Beckmann CF, Mackay CE. Distinct patterns of brain activity in young carriers of the APOE-epsilon4 allele. Proc Natl Acad Sci USA. 2009; 47:7209. https://doi.org/10.1073/ pnas.0811879106.

42. Buckner RL, Snyder AZ, Shannon BJ, Larossa G, Sachs R, Fotenos AF, Sheline YI, Klunk WE, Mathis CA, Morris JC. Molecular, Structural, and Functional Characterization of Alzheimer's Disease: Evidence for a Relationship between Default Activity, Amyloid, and Memory. Journal of Neuroscience the Official Journal of the Society for Neuroscience. 2005; 25:7709. https://doi.org/10.1523/ JNEUROSCI.2177-05.2005.

43. Carmelli D, Decarli C, Swan GE, Kellyhayes M, Wolf PA, Reed T, Guralnik JM. The joint effect of apolipoprotein E epsilon4 and MRI findings on lower-extremity function and decline in cognitive function. Journals of Gerontology. 2000; 55:M103. https://doi.org/10.1093/gerona/55.2.M103.

44. Melzer D, Dik MG, van Kamp GJ, Jonker C, Deeg DJ. The apolipoprotein E e4 polymorphism is strongly associated with poor mobility performance test results but not selfreported limitation in older people. Journals of Gerontology. 2005; 60:1319. https://doi.org/10.1093/gerona/60.10.1319.

45. Cheung MM, Hui ES, Chan KC, Helpern JA, Qi L, Wu EX. Does diffusion kurtosis imaging lead to better neural tissue characterization? A rodent brain maturation study. Neuroimage. 2009; 45:386-92. https://doi.org/10.1016/j. neuroimage.2008.12.018.

46. Das SK, Wang JL, Bing L, Bhetuwal A, Yang HF. Regional Values of Diffusional Kurtosis Estimates in the Healthy Brain during Normal Aging. Clin Neuroradiol. 2016. https:// doi.org/10.1007/s00062-015-0490-z.

47. Latt J, Nilsson M, Wirestam R, Stahlberg F, Karlsson N, Johansson M, Sundgren PC, van Westen D. Regional values of diffusional kurtosis estimates in the healthy brain. J Magn Reson Imaging. 2013; 37:610-8. https://doi.org/10.1002/ jmri.23857.

48. Filippini N, MacIntosh BJ, Hough MG, Goodwin GM, Frisoni GB, Smith SM, Matthews PM, Beckmann CF, Mackay CE. Distinct patterns of brain activity in young carriers of the APOE-epsilon4 allele. Proc Natl Acad Sci USA. 2009; 106:7209-14. https://doi.org/10.1073/ pnas.0811879106.

49. Zhu J, Zhuo C, Qin W, Wang D, Ma X, Zhou Y, Yu C. Performances of diffusion kurtosis imaging and diffusion tensor imaging in detecting white matter abnormality in schizophrenia. Neuroimage Clin. 2015; 7:170-6. https:// doi.org/10.1016/j.nicl.2014.12.008. 